\title{
Saving a seat at the table for community members: co-creating an attachment-based intervention for low-income Latinx parent-youth dyads using a promotor/a model
}

\author{
Jessica L. Borelli, ${ }^{1}$ Lyric N. Russo, ${ }^{1}$ Jose Arreola, ${ }^{1}$ Breana R. Cervantes, ${ }^{1}$ Christina M. Marquez, ${ }^{1}$ Gloria Montiel, ${ }^{2}$ \\ Jaqueline Carballo, ${ }^{1}$ Vanessa Avalos, ${ }^{1}$ Jackie Garcia, ${ }^{1}$ Isha Bhatt, ${ }^{1}$ Gina Torres,${ }^{2}$ Francisca Leal, ${ }^{2}$ Nancy Guerra ${ }^{1}$
}

Correspondence: Jessica L. Borelli, 4201 Social and Behavioral Sciences Gateway, Irvine, CA, 92697, USA.

Tel.: +1.949.824.1174.

E-mail: jessica.borelli@uci.edu

Citation: Borelli, J. L., Russo, L. N., Arreola, J., Cervantes, B. R., Marquez, C.M., Montiel, G., Carballo, J., Avalos, V., Garcia, J., Bhatt, I., Torres, G., Leal, F., \& Guerra, N. (2022). Saving a seat at the table for community members: co-creating an attachment-based intervention for low-income Latinx parent-youth dyads using a promotor/a model. Research in Psychotherapy: Psychopathology, Process and Outcome, 25(1), 39-56. doi: 10.4081/ripppo.2022.598

Acknowledgements: we would like to acknowledge the contributions of the promotors at Latino Health Access: Araceli Robles, Noraima Chirinos, Irma Macias, and Socorro Juarez, who were the promotors leading the madres groups for the program; Moises Vazquez, Christina Marquez, Isha Bhatt, and Gina Torres, who were the promotoras leading the youth groups for the study; Verenice Escobar, who served as the Emotional Wellness Program Assistant; Catalina Garci and Victoria Garcia who helped with participant recruitment for the program; and the countless research assistants from the UCI THRIVE Laboratory who assisted with every step of this project. Gina Torres also served as a coordinator for the project. We would also like to acknowledge our funding agency (the Centres for Disease Control and Prevention: 1R01CE002907: PIs Guerra and Borelli), whose generosity was essential in supporting this program.

Contributions: all authors significantly contributed to the production and completion of this manuscript.

Conflicts of interest: the authors declare no potential conflicts of interest.

Availability of data and material: the data that support the findings of this study are available upon request from the corresponding author (JB).

Ethical approval and consent to participate: this study was approved by the UCI Institutional Review Board (HS\# 2017-3974) and informed consent was obtained from all participants.

See online Appendix for additional Table.

Received for publication: 19 November 2021.

Revision received: 15 December 2021.

Accepted for publication: 15 December 2021.

This work is licensed under a Creative Commons Attribution NonCommercial 4.0 License (CC BY-NC 4.0).

${ }^{\circ}$ Copyright: the Author(s), 2022

Licensee PAGEPress, Italy

Research in Psychotherapy:

Psychopathology, Process and Outcome 2022; 25:39-56

doi:10.4081/ripppo.2022.598
${ }^{1}$ University of California, Irvine; ${ }^{2}$ Latino Health Access, Santa Ana, CA, USA

\begin{abstract}
Evidence for the effectiveness of attachment-based interventions in improving youth's socioemotional health increases each year, yet potential for scalability of existing programs is limited. Available programs may have lower acceptability within low-income immigrant communities. Co-designing and implementing interventions with trained community workers (Promotors) offers an appealing solution to multiple challenges, but community workers must have high investment in the program for this to be a workable solution. This study examines the experiences of promotors involved in the co-creation and delivery of an attachmentbased intervention program for low-income Latinx youth (ages 8 to 17$)$ and their mothers. Promotors $(N=8)$ completed surveys, reporting on the experiences of each therapy group in terms of group dynamic (e.g., promotors' connectedness to each group, perceived program relevance). Following the completion of the intervention study, promotors participated in interviews in which they described their experiences in co-creating the intervention, delivering the intervention to the community, and their recommendations for improving the intervention. Overall, promotors perceived group dynamics as positive, though the mother groups were evaluated as significantly higher in quality (e.g., lower conflict) than the youth groups. Interviews revealed that promotors enjoyed the cocreation process and identified important areas for improvements for the intervention (incorporation of more visuals, creation of agelimited groups, reducing number of youth sessions) and evaluation (reduction in length, modification of language). Integrating input from promotors in the process of co-creating and implementing an intervention can benefit every member of the community from the program participants to the providers themselves.
\end{abstract}

Key words: Attachment; intervention; promotor model; Latinx; community-based participatory research.

\section{Saving a seat at the table for community members: co-creating an attachment-based intervention for low-income Latinx parent-youth dyads using a promotor/a model}

Latinx communities face numerous obstacles to accessing mental health services, including language barriers, limited-service availability and affordability, and lack of culturally competent services (Rastogi et al., 2012), which contribute to the disparities in both access and quality of 
mental health services. Community-based participatory research (CBPR), which combines equitable contributions from both researchers and community members, offers a potential solution to reducing mental health disparities (Israel et al., 1998). Collaboration often involves trained community workers (Promotors; Martin, 2005), but few studies have examined promotors' experiences in co-developing intervention strategies. Promotor/a experiences provide a unique perspective as they are both community members and integral members of the research team. Understanding promotors' experiences may help strengthen the collaboration process between research and community members, yielding more sustainable collaborations and better interventions. This study examined the experiences of promotors involved in co-creating and delivering an attachment-based intervention.

\section{Attachment-based intervention models for improving youth mental health}

Intervention models that seek to improve parent-child relationship quality as a means of improving youth wellbeing are effective (Ryan et al., 2017; Thomas \& ZimmerGembeck, 2007). Existing intervention programs focus on different treatment targets - for instance, some programs teach parents positive child-rearing strategies (e.g., Triple P-Positive Parenting Program; Thomas \& Zimmer-Gembeck, 2007), others focus on enhancing closeness between parents and children (e.g., Parent-Child Interaction Therapy; Thomas et al., 2017), and yet others focus on improving communication between parents and children (e.g., Child and Family Traumatic Stress Intervention: Hahn et al., 2015).

Attachment theory emphasizes the protective function of relationships and posits that experiences with parents during childhood lead to internal working models of the self and of the parent-child relationship (Bowlby, 1973). According to attachment theory, children are biologically predisposed to use their parents as a secure base to explore from and a safe haven to return to in times of distress (Ainsworth et al., 1978). Children who receive consistent and sensitive responses from caregivers tend to exhibit more secure base and safe haven behaviours and are more likely to develop securely attached relationships with their parents, as well as an internal working model that reflects a relationship where needs are appropriately met (Ainsworth et al., 1978; Kerns et al., 2015). Insensitive, inappropriate, or mistimed responses to a child's needs, in comparison, may lead to an insecure attachment, as the caregiver's seeming inability to successfully protect or tend to the child may cause the child to develop an internal working model that views others as untrustworthy and themselves as not deserving of reliable, sensitive care (Ainsworth et al., 1978). Unsurprisingly, insecure attachment is associated with the development of more relational, behavioral, and affective difficulties (Dagnino et al., 2017;
Kerns \& Brumariu, 2014; Roelofs et al., 2006), while secure attachment is associated with more optimal developmental outcomes (Alhusen et al., 2013; Del Villano et al., 2014). More hopeful, however, is the conclusion that attachment security is malleable (Beijersbergen et al., 2012; D'Onofrio et al., 2015), with increases in sensitive parenting from early childhood to adolescence predicting changes from insecure attachment in infancy to secure attachment in adolescence (Beijersbergen et al., 2012), highlighting the need for attachment-based interventions.

Attachment theory's conceptualization of parental sensitivity and the role of internal working models offers a valuable framework for interventions that aim to improve child outcomes by supporting parents with strategies to enhance caregiving quality and promote attachment security. Attachment-based interventions are effective at increasing parental sensitivity and reducing the risk of children's attachment insecurity (Bakermans-Kranenburg et al., 2003). For instance, Steele and colleagues (2014) found an attachment-based video feedback intervention, which uses recorded observations of parent-child interactions to explore and reveal deeper emotions and meaning that underlie parent-child behaviour, to be effective in promoting maternal sensitivity and reducing problem behaviour in children. Attachment-based interventions have also demonstrated improvements in mental health for both parents and children (Cicchetti et al., 2006; Moretti et al., 2015), highlighting the utility of this framework across intervention styles and aims. Together, these findings illustrate the benefits of implementing attachment-based interventions.

\section{Meeting the needs of Latinx youth in immigrant communities}

While existing attachment-based intervention groups have yielded impressive outcomes within the communities in which they have been implemented (e.g., Pace et al., 2016; Steele et al., 2014), there are still many limitations that come with intervention groups developed and led primarily by academic researchers without community guidance. Attachment-based intervention groups have previously been focused on changing participants' behaviour rather than providing culturally appropriate social support, or support that can be accessed continuously, alongside their intervention curriculum (Diamond et al., 2010; Dozier \& Bernard, 2017). Latinx immigrant communities, in particular, face persistent and ongoing risk factors that threaten their daily mental wellness (e.g., loss of social groups, poverty, and limited communication due to language barriers; Lee et al., 2020). Additionally, Latinx youth who grow up in immigrant families are at increased risk of experiencing anxiety as a result of immigration enforcement fear, discrimination, and trauma-exposure (Cardoso et al., 2021), presenting an additional barrier to accessing health services in today's climate (Barnett et al., 2018; Held et al., 2020). Such barriers can be mediated 
with the use of continuous social support and resources from community-based intervention groups that protect and strengthen cultural values (Lee et al., 2020).

The promotor/a model entails a community-based system for providing health-related care, support, and education to increase access to culturally-informed mental health services and interventions among underserved and marginalized communities (Barnett et al., 2018; Elder et al., 2019). This model exhibits strengths in addressing cultural and linguistic barriers via culturally-driven health education and outreach (Messias et al., 2013; Rhodes et al., 2007; Tran et al., 2014; Waitzkin et al., 2011). Through the delivery and dissemination of culturally-responsive mental health resources to Latinx families, promotors act as 'bridges' between their communities and formal health care providers (Barnett et al., 2018; Rhodes et al., 2007; Tran et al., 2014). Perhaps because they share the cultural values of those they serve, such as familismo [a cultural value emphasizing close, supportive, warm family relationships (Campos et al., 2014)], they can help them more effectively communicate with health care providers (Hoeft et al., 2015; Shepherd-Banigan et al., 2014). When working in the context of community and university partnerships, promotors can effectively mobilize communities, mitigate mental health stigma, increase treatment and research engagement, as well as equip community members with the knowledge and practice of self-care and health promotive behaviours (Barnett et al., 2018; 2019; Elder et al., 2009; Sternberg et al., 2019). Additionally, promotors and community members benefit from such collaborations through the provision of training and resources (Kakuma et al., 2011; Messias et al., 2013). Active promotor/a involvement in the research process is critical in integrating community-based insights, experiences, and perspectives to the development and implementation of interventions and measures, while also securing the community's trust and enhancing the cultural relevance of the research itself (Infante et al., 2011). When working in the context of community and university partnerships, promotors can effectively mobilize communities, mitigate mental health stigma, increase treatment and research engagement, as well as equip community members with the knowledge and practice of self-care and health promotive behaviours (Barnett et al., 2018; 2019; Elder et al., 2009; Sternberg et al., 2019). Additionally, promotors and community members benefit from such collaborations through the provision of training and resources (Kakuma et al., 2011; Messias et al., 2013). Active promotor/a involvement in the research process is critical in integrating community-based insights, experiences, and perspectives to the development and implementation of interventions and measures, while also securing the community's trust and enhancing the cultural relevance of the research itself (Infante et al., 2011).

In addition to the potential lack of cultural congruence, existing attachment-based therapy models also pose limits on meeting global mental health needs in terms of labour, clinicians' educational degree level and training, and the accessibility of delivering such interventions in rural contexts (Infante et al., 2011). Mental health disparities are most commonly experienced among children who come from historically marginalized populations and rural communities, yet access to mental health services is minimal due to unemployment rates and lack of career growth opportunities for clinicians/providers (Kataoka et al., 2010). Thus, equipping attachment-based therapy models with the promotor/a model may offer a unique solution to prominent issues such as treatment delivery, access, and utilization within these communities. Promotor/a-led interventions not only increase health care access but can also provide costeffective care in underserved communities (Barnett et al., 2019; Waitzkin et al., 2011), while concurrently strengthening family and communal bonds and reaching communities that may be wary of healthcare professionals (Barnett et al., 2018; Tran et al., 2014).

Furthermore, the number of formal community mental health professionals that can deliver linguistically and culturally competent care is inadequate to address the various needs of marginalized communities such as the Latinx population (Bruckner et al., 2011; Kakuma et al., 2011). The communities where the promotors' presence is needed are the areas where preventive health care methodologies are often neglected. While current attachment-based programs prove to be effective, they often require a carefully selected group of participants and specialized highly trained clinicians (Kataoka et al., 2010). Latinx immigrant communities require more accessibility to care in addition to clinicians/ educators who understand the environments that impact their lives. The promotor/a model offers a solution, as promotors are often trusted members within these same communities/localities, allowing for a sense of belonging and shared experience (Messias et al., 2013).

In these underserved and under-resourced settings, promotors under rigorous training and supervision via community-university partnerships may even take on the role of primary service providers (Barnett et al., 2019; Sternberg et al., 2019; Tran et al., 2014; Waitzkin et al., 2011). Evidence-based protocols delivered by promotors may lead to positive mental health outcomes (Barnett et al., 2019; Singla et al., 2017; Sternberg et al., 2019). For example, Sternberg and colleagues (2019) successfully trained promotoras to deliver cognitive-behavioral stress management programs to Latinx immigrant communities within a community health setting. Promotoras demonstrated excellent fidelity and improvements in their knowledge and application of stress and mood management techniques (Sternberg et al., 2019). Findings from a meta-analysis demonstrated moderate to large effect sizes in symptom reduction for adults receiving psychological treatment delivered by nonspecialist providers such as community health workers (i.e., promotors; Singla et al., 2017), highlighting the utility of community-university partnerships implementing promotor/a-led programs within low-resource settings to effec- 
tively provide mental health treatment and address cultural and linguistic barriers.

\section{Understanding the promotor/a experience of delivering co-developed interventions}

Co-designing and implementing interventions with Promotors offers an appealing solution to multiple challenges that traditional attachment-based interventions may face. Promotors serve as a bridge to members within the collaboration, establishing a trusting connection between health professionals and the Latinx families they serve (Borelli, Cervantes, et al., 2021; Falbe et al., 2017). Recognizing the trust that promotors are able to establish with community participants provides a unique opportunity for mental health professionals that seek to provide psychoeducational intervention programs to promote positive psychological outcomes among Latinx communities. The inclusion of promotors in the development and implementation of a community based health program can help to reduce barriers that Latinx families may experience in seeking healthcare (Arredondo et al, 2021). Empowering promotors to 'join us at the table' in co-designing a promotor/a-led, culturally tailored, group-based intervention within the community can help to promote health equity (Arredondo et al., 2021).

However, in order for these dreams to be realized, promotors really do need to have a seat at the table. The collaborative process needs to be inclusive, and promotors' voices must be heard, respected, and honoured in the conversation (Elder et al., 2009; Infante et al., 2011). The resultant intervention must be reflective of the local knowledge that promotors bring to the collaborative process (Infante et al., 2011). In an ideal CBPR process, both the academics and the community workers will grow from the experience, with their personal and professional lives becoming enriched as a result of the collaboration (Bracho et al., 2016). In order to ascertain whether this goal has been achieved, it is imperative to assess the promotors' perceptions of their experiences of the co-design process and evaluations of the resultant intervention program.

\section{Current investigation}

The Confia en Mi, Confio en Ti intervention (Borelli et al., 2021) is a manualized attachment-based, psychosocial program for Latinx mothers and youth, co-designed and cofacilitated by university researchers and community agency members from a local, non-profit community organization in Southern California. Resulting from a four-year partnership rooted in the CBPR model, this intervention program was designed from start to finish by all stakeholders - promotors, community agency administrators, university researchers - and executed exclusively by the promotors. This 8-week program is guided by core principles of attachment theory, aiming to strengthen attachment security (e.g., secure base, safe haven behaviours) between mothers and youth between the ages of 8 and 17 through weekly discussions and activities promoting positive parenting strategies, fostering youth autonomy, and reducing youth violence within the community. The promotors were at the forefront of curriculum development and integral to determining several aspects of the content, including what was most relevant and culturally appropriate for the needs of their community and the medium and frequency of the material presented to the families. Through their personal experiences living in the community and additional training and expertise as community workers, the promotors organically established rapport with families and maintained relationships with these families even past participation in the intervention - a reminder of the promotors' mission to serve as a resource to their community and act as a bridge for their neighbours to be able to receive assistance from their local community agency (Borelli et al., 2021).

The present study seeks to examine the perspectives of promotors by reflecting on their involvement in the development and implementation of an attachment-based intervention. Attachment-based interventions are relational in nature, providing a clear pathway for the inclusion of concepts that mirror the significance of familismo (e.g., the importance of social support) within Latinx families. We build upon the existing literature demonstrating the significant role promotors have in promoting health equity within the Latinx community. Including promotors in the development of the intervention curriculum allowed us to translate the psychological constructs discussed in attachment research (e.g., secure base and safe haven) into a more palatable way of explaining the mechanisms of attachment that made room for the inclusion of metaphorical concepts that were more closely related to the experience of the community. The goal of the current study is to examine the experiences of promotors involved in co-creating and delivering an attachment-based intervention. We accomplish this goal through assuming a mixed-methods approach via two mechanisms: i) Evaluating quantitative data assessing group dynamics collected after the conclusion of each 8week therapy group; and ii) evaluating the personal and professional impacts of the collaborative and intervention delivery process on the promotors through the qualitative analysis of a semistructured interview administered to the promotors at the conclusion of the study. In so doing, we ask the following research questions: How do promotors evaluate the quality of the mother and youth aims of the attachment-based intervention program (RQ1, assessed via quantitative and qualitative data)? Specifically, do the promotors indicate a high level of overall quality of the program (RQ1a)? And do the promotors evaluate the mother component or the youth component more favourably (RQ1b)? What themes emerge when they discuss the quality of the intervention (RQ1c)? 
Next, we turn to examining the process of co-creating the intervention, asking the following research questions using an interview administered to promotors at the end of the 4-year research collaboration: How do promotors think and feel about the process of co-developing and delivering an attachment-based intervention (RQ2)? How do promotorles think and feel about co-developing an attachmentbased intervention (RQ2a)? How do promotors think and feel about the final curriculum developed (RQ2b)? How do promotors think and feel about implementing an attachment-based curriculum (RQ2c)? And how do promotors think and feel about the impact of delivering the curriculum (RQ2d)? The answers to these questions have implications for the future design, development, and implementation of attachment-based interventions in collaboration with promotors within community agencies serving low income Latinx families.

\section{Materials and methods}

\section{Participants and procedure}

The protocol for this study was approved by the Institutional Review Board prior to the inception of data collection (HS\# 2017-3974). Participants for this study were promotors at Latino Health Access (LHA) who were involved in co-designing and delivering the attachment-based intervention to families. There are two components to this study (quantitative survey and qualitative interview) and the participants were mostly overlapping but not completely identical in each portion of the study.

The quantitative surveys were administered to the promotors who led the mothers and youth groups at the conclusion of each group cycle, which consisted of groups led for mothers and groups led for their children/teens in parallel. In total, there were 11 group cycles throughout the study. Each group cycle was comprised of between 5 and 19 mothers $\left(M_{\text {age }} 41.19, S D_{\text {age }}=6.66\right)$ and the same number of youth ( $M_{\text {age }}=12.06, S D_{\text {age }}=2.11 ; 45.3 \%$ female). On average, the families participating in the study were low income (mean household income $=\$ 26,386, S D=\$ 12,328$ ), with $27.3 \%$ of mothers reporting they had experienced food insecurity in the past year. Mothers and youth participating in the program were recruited for this study by promotors who invited families to participate in a family wellness program offered through a university partnership with the community health agency. Recruitment took place at local shopping centres, community events, churches, and schools. Recruitment flyers were also posted throughout LHA. Eligibility included having a child in the desired age range who was free of developmental disability or severe mental illness (e.g., psychosis) and residing in one of the target neighbourhoods selected by the researchers due to elevated risk for poverty and exposure to violence. Most $(97.2 \%)$ of the mothers reported they had not been born in the United States, with the largest percentage of the sample having been born in Mexico (90.7\%). Mothers provided informed consent for participation and youth provided informed assent.

Of note is that the promotors on staff at LHA reside in the community that they serve and match the community in terms of demographics - in other words, they share similar education level, income level, and ethnic identity of the families who receive services at LHA. In the current study, administrators from LHA selected promotors to lead the mother groups among those already on staff at the agency based on a predetermined set of characteristics (being warm, feeling comfortable teaching and speaking with groups, showing skill in relationship building) and having availability in their work schedules. Two promotors were identified through the primary group leaders and assisted in the development of the intervention. A total of $n=4$ promotoras $\left(M_{\text {age }}=55.75,100 \%\right.$ female, $100 \%$ Latina, $66.7 \%$ born in Mexico, 33.3\% born in in Venezuela, all LHA staff; mean household income $=\$ 51,666.67, S D=\$ 7,637.63$ ) led the mother groups after training in the intervention administration with the Principal Investigator. These 4 promotoras completed these surveys that comprise the quantitative portion of the current investigation.

The administrators at LHA and the university research team collaboratively selected the youth promotors from two pools of candidates: i) those promotors already on staff at LHA who had previously been involved with other youth groups; and ii) graduate-level and undergraduate research assistants who were members of the lead researcher's laboratory. Henceforth, we refer to the graduate-level research assistants as facilitators. The team made selections based on candidates' skills interacting with youth (high energy, relatable, youthful) and ability to disseminate intervention information in an interactive, engaging, and accurate manner. The composition of the youth promotor/a group was more diverse compared to the promotoras who led the mother groups - specifically, we integrated university research assistants $(n=3)$ and facilitators $(n=2)$ with LHA promotors to lead the youth groups. This recruitment process yielded a total of $n=7$ promotors $\left(M_{\text {age }}=33.86 ; 71.4 \%\right.$ female, $28.60 \%$ male; $85.71 \%$ Latinx, $14.29 \%$ South Asian; mean household income $=\$ 55,411.00, S D=\$ 21,466.42)$ to lead the youth groups across the study period; these promotors completed the surveys comprising the quantitative portion of the current study. Of note is that the university research assistants were never solely in charge of running the groups single-handedly (there was always both a LHA promotor/a and a UCI facilitator in that role), but they did have a leadership role and therefore we considered their feedback to be important.

The qualitative interviews were conducted at the end of the four-year study period. The purpose of this assessment was to capture the promotors' sentiments regarding the process of collaboration, including co-designing the intervention, delivering the intervention to the community, and 
reflecting on how the intervention was received by the program participants. The interview respondents $(N=8 ; 87.5 \%$ female, $12.5 \%$ male) included all LHA promotors and the 2 UCI group facilitators. In other words, all participants who were administered the survey were also administered the interview, except for the $3 \mathrm{UCI}$ research assistants, who took only the quantitative survey described in the section above, not the interview.

\section{Measures}

Group dynamics survey. Using a questionnaire designed for the purpose of this investigation, the promotors responded to 11 questions that broadly probed their perceptions of the intervention. The first 7 questions were multiple choice and assessed intervention appeal ('How relevant was the content (concepts, themes, worksheets, activities) to the group members' lives?'), the degree of interpersonal connectedness between group members and promotors (e.g., 'How connected do you feel to the group members as a whole?,' 'What is the main takeaway you have from leading this group?'), and the quality of group members' participation (e.g., 'How honest/open were the group members to sharing their experiences and hearing others' experiences?'). Six questions involved the following Likert-style responses: $1=$ Not at all, $2=A$ little bit, 3=Moderately, 4=Quite $a$ bit, and 5=Extremely. One question gauging conflict among group members was assessed using a different set of Likert-style responses: $1=$ Never, $2=$ Rarely, $3=$ Sometimes, $4=O f t e n$, and $5=\mathrm{Al}$ ways. Lastly, the final 4 questions were open-response format and probed: number of sessions the promotors were absent, interesting or unusual observations of the group, main takeaways from leading the group, and final comments or suggestions about the group. We were missing data from one round of the intervention administration from the mother promotors for the multiple-choice quantitative data portion (i.e., the promotor/a who led the group only provided responses to the four open-response questions); thus, we have complete group dynamics survey data from 10 mother groups and 11 youth groups.

RQ1 data analytic approach. To analyse RQ1, we adopted a mixed method approach. Specifically, we examined the mean responses across the promotors to the survey questions. We were interested in evaluating whether their responses exceeded a certain predetermined threshold. For positively worded questions (i.e., those evaluating positive attributes or constructs), we were hoping to see mean scores of 3 (moderately) or higher and for the negatively worded question (the question assessing conflict between group members), we hoped to see a mean score of 2 or lower (rarely/never). To analyse RQ1b, we conducted paired samples $t$-tests comparing the mean scores for the promotors that led the mother groups and the promotors that led the youth groups on the 4 different closed-ended questions asked following both groups. Significant differences in these $t$-tests would indicate differences between the mother and youth groups in promotors' perception of the quality of the group dynamic. To analyse RQ1c, we examined excerpts from the text responses promotors' provided to our open-ended questions, evaluating themes that emerged repeatedly from the narratives. Given that we had less data for these narrative responses than in our interviews used to address RQ2 (see below), we did not conduct a formal thematic analysis for RQ1c.

Personal and professional impacts interview. Using a semi-structured interview designed for the purpose of this study, the promotors responded to 10 questions regarding their experiences throughout the process of collaborating on this project (complete interview presented in Table 1). The development of the questions was informed by the analysis of prior interviews conducted with the promotors halfway through the collaboration, which revealed some important insights regarding the challenges and opportunities the promotors perceived in this project (see Borelli, Cervantes et al., 2021). As such, the resultant questions in the current interview focused on promotors' experiences of intervention co-development (e.g., 'To what extent did you feel like you were able to contribute your ideas to the curriculum?'), the intervention curriculum that resulted from the co-development process (e.g., 'What were the strengths of this curriculum?', 'What were the weaknesses of this curriculum?', 'What recommendations do you have for improving the curriculum?'), and program and curriculum implementation (e.g., 'What recommendations do you have for improving program delivery?'). Finally, the interview contained questions regarding the impact of delivering the curriculum on promotors in terms of what they learned about themselves and their community (e.g., 'What did you learn about your community as a result of delivering the curriculum?'), as well as in terms of how delivering this curriculum impacted their life and their work (e.g., 'How has delivering this curriculum affected your life?').

RQ2 Qualitative data analytic approach. The research team employed a qualitative data analytic approach to answering the second research question: How do promotors think and feel about the process of co-developing and delivering an attachment-based intervention (RQ2)? Audio recordings of the promotor/a interviews were de-identified and stored on an encrypted server. Interview responses were transcribed, de-identified, and stored on the same server. The researchers' approach to the qualitative analysis followed a six-step procedure known as Thematic Analysis (TA) outlined by Braun \& Clarke (2012). The coding procedure included reviewing transcripts and extracting themes (also referred to as codes). The rating team consisted of four student research assistants (self-identified as Latinx female) - all paper authors. Note that coding was done in the language in which the interviews were conducted (i.e., interviews conducted in Spanish were coded in Spanish), however, for ease of interpretation here, we 
present all translated or English excerpts. For original and complete themes in their original language, see Table S1 in Appendix.

Thematic analysis. In the first phase of the thematic analysis approach, the rating team reviewed a total of 129 unique responses compiled within the data collected from the transcribed interviews. After each member of the team had the opportunity to review the data, the raters independently coded the verbatims. The raters agreed on the following codes to consider when independently reviewing the verbatims: i) participant retention; ii) recruitment; iii) attendance; iv) engaging promotors; v) promotor/a buy-in; vi) engaging mothers; vii) engaging youth; viii) parent-child relationships; ix) real life application; $\mathrm{x}$ ) trauma-informed; xi) community connectedness; and xii) takeaways. Next, the lead coder compiled the coded verbatims into one aggregate data file and identified 129 total unique verbatims that had been assigned at least one code by one rater. Based on the initial coding exercise, 107 coded verbatims had achieved acceptable or absolute agreement (75\%-100\%) across all four raters to include these verbatims in the final analysis. The rating team met to discuss the initial findings and review the remaining coded verbatims that had achieved at least $50 \%$ agreement across raters in the first coding activity. As a result of this discussion, the coders reviewed all verbatims for a third time, re-coding the data to include only verbatims that reached acceptable or absolute agreement (75\%-100\%), using 'negotiated agreement' practices to resolve coding disagreement where relevant (Campbell et al., 2013). Total coded verbatims increased from 107 to 128 as a result of negotiating verbatims that had achieved less than acceptable agreement (50\%) and re-coding the verbatims with agreement percentages of $25 \%-50 \%$. All members of the rating team reviewed the data for important extracts and/or full verbatims to highlight in the final analyses. Finally, as the last phase of thematic analysis requires generating a compelling story, the coders began to formally write up the findings.

Inter-rater coding agreement. In an effort to reduce coding errors, interrater agreement (IRA) was considered. While there is little consensus within the existing qualitative literature in regard to including measures of agreement, the coding team participated in a collaborative approach to coding the data and computed a percentage of agreement for every verbatim assigned a given code (Campbell et al., 2013; LeBreton \& Senter, 2008). Distinguished from other measures of reliability, IRA considers agreement based upon consensus achieved between all members of the coding team (LeBreton \& Senter, 2008).

\section{Table 1. Questions posed to the promotors that co-developed and implemented the curriculum.}

English

1.) How was this experience for you overall? What were some of the positives and negatives of the experience?

2.) To what extent did you feel like you were able to contribute your ideas to the curriculum?

3.) What would you say were the strengths of the curriculum?

4) What were the weaknesses of the curriculum?

5.) What recommendations do you have for improving the curriculum?

6.) What recommendations do you have for improving the program delivery?

7.) What did you learn about your community as a result of delivering the curriculum?

8.) What did you learn about yourself as a result of delivering the curriculum?

9.) Has delivering this curriculum affected other aspects of your work?

10.) How has delivering the curriculum affected your life as a whole?

Spanish

1.) ¿En general como a sentido la experiencia de los grupos? ¿Cuáles son las cosas positivas y negativas de esta experiencia?

2.) ¿A qué grado siento que pudo contribuir sus ideas al currículo?

3.) ¿Cuáles fueron las fortalezas del currículo?

4) ¿Cuáles fueron las debilidades del currículo?

5.) ¿Qué recomendaciones tiene para mejorar el currículo?

6.) ¿Qué recomendaciones tiene para mejorar la entrega del programa?

7.) ¿Qué aprendió acerca de su comunidad como resultado de los grupos?

8.) ¿Qué aprendió acerca de si misma como resultado de los grupos?

9.) ¿Como ha cambiado otras partes de su trabajo el currículo del grupo?

10.) ¿Y cómo ha afectado su vida la entrega del currículo? 


\section{Results}

Bivariate correlations revealed that greater connectedness between the promotors who led the mothers group and the participants in the mothers group was associated with stronger relationships between the group participants, $r=0.64, \mathrm{P}=0.048$; likewise, the greater the connectedness between the promotors who led the youth groups and the youth participants, the stronger the relationships among the youth group members, $r=0.83, \mathrm{P}=0.001$. Greater conflict between participants in the youth group was associated with lesser likelihood of the group members participating in future groups at Latino Health Access, $r=-0.82, \mathrm{P}=0.004$.

\section{RQ1: How do promotors assess the quality} of the mother and youth aims of the attachment-based intervention program (assessed via quantitative and qualitative data)?

To address RQ1, we examined our quantitative and our qualitative data that was gathered at the conclusion of each cycle of the 8-week mother and youth groups (11 in total). Means to each question asked of promotors from the quantitative data are presented in Table 2 - all scores on this questionnaire had a possible range of 1 to 5 , though in actuality the range was much narrower.

\section{RQ1a: Do the promotors indicate a high level of overall quality of the program?}

To evaluate RQ1a, we examined the means for the survey questions completed by the promotors relative to the expected values. On average, the promotors who led the youth group felt moderately connected to the youth participants, that the youth participants got along moderately well with one another, and that the content was moderately relevant to the youth. They reported that there was seldom to sometimes conflict between the members of the youth group. In terms of the mother groups, on the whole the means were higher - the promotors who led the mothers group rated themselves as being quite a bit to extremely connected to the mother participants, and similarly indicated that content was quite a bit to extremely relevant, and

Table 2. Promotors $(\mathrm{N}=8)$ perceptions of therapy group dynamics.

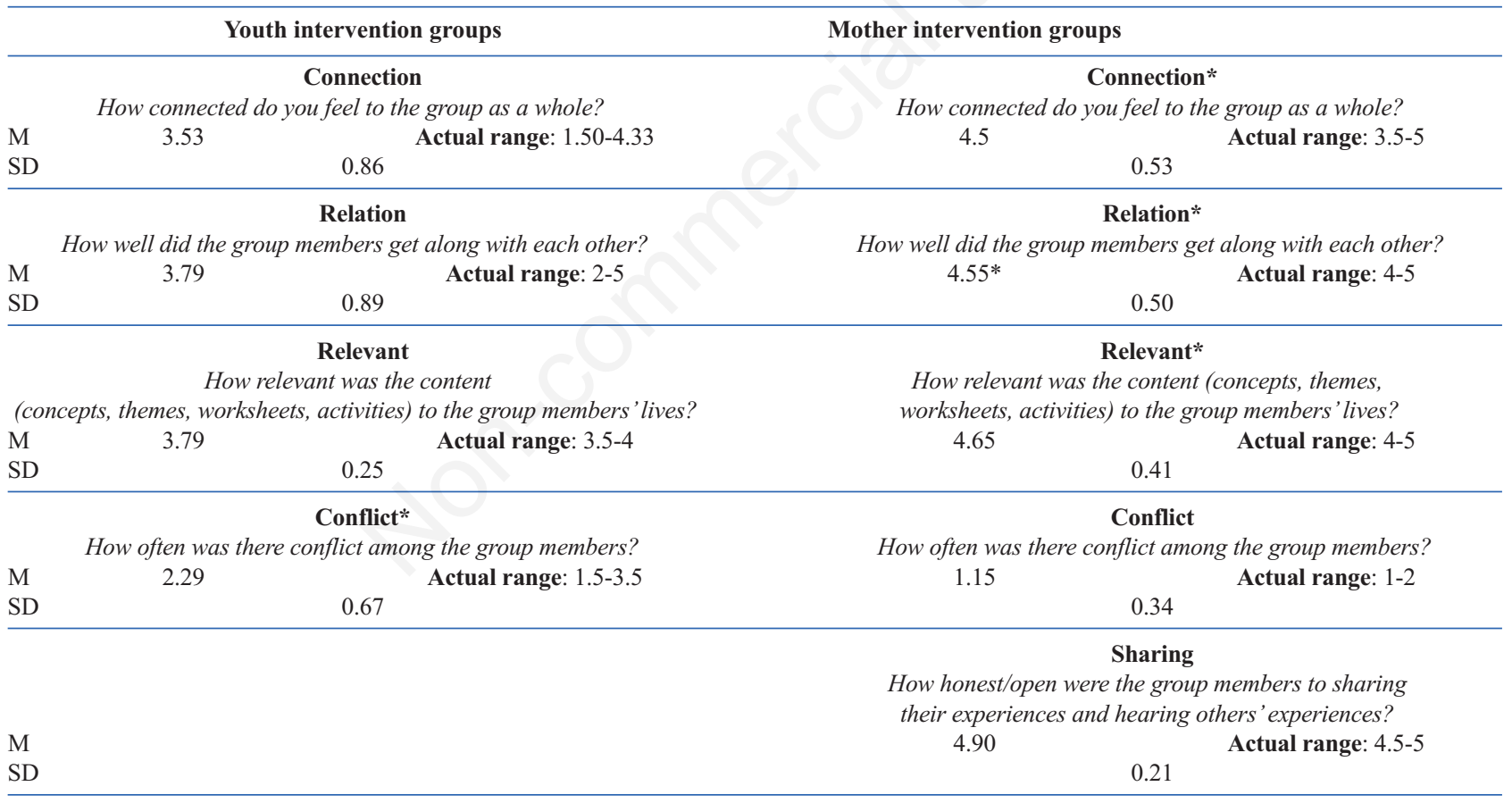

Emotion

How emotional were the group members when sharing their experiences and hearing others' experiences?

$\begin{array}{lr}\mathrm{M} & \text { Actual range: 4-5 } \\ \mathrm{SD} & 4.86 \quad 0.24\end{array}$

Future

How much interest did the group members show in participating in future programs/ groups? 
that the group members got along quite a bit to extremely well. They rated how honest and open the group members were, how emotional the members were, and how much interest the members showed in participating in future programs as quite a bit. Likewise, the promotors evaluated the mothers as showing low levels of conflict, falling between never and rarely. Thus, we conclude that these data support our hypotheses, as promotors indicate a moderately high level of overall program quality of the youth program and a high level of program quality of the mother program.

\section{RQ1b: Do the promotors evaluate the mother component or the youth component more favourably?}

To examine RQ1b, we conducted a series of pairedsamples $t$-tests in which we compared the means for the four scales that were identical across the youth and mother groups to examine whether youth and mother groups differed in their quality as evaluated by the promotors.

In terms of level of connectedness, the results of a paired samples $t$-test revealed that the promotors leading the mother groups rated themselves as significantly more connected to the groups than the promotors leading the youth groups, $t(9)=3.70, \mathrm{P}=0.005$.

In terms of quality of the relationships among group members, the promotors reported that the quality of relationships among participants in the mothers' groups were higher in quality compared to the promotor/a reported relationship quality of participants in the youth groups, $t(9)=3.11, \mathrm{P}=0.01$.

In terms of program relevance, the promotors reported that the intervention curriculum was significantly more relevant for the mothers' groups compared to the intervention curriculum presented to the youth groups, $t(6)=5.84$, $\mathrm{P}<0.001$.

Finally, in terms of conflict between group members, the promotors working with the mother groups reported significantly less group conflict than the promotors working with the youth groups, $t(6)=-5.26, \mathrm{P}<0.001$.

\section{RQ1c: What themes emerge when they discuss the quality of the intervention?}

To evaluate RQ1c, we examined the qualitative responses from the promotors, as depicted in Tables 2 and 3. First we discuss the responses from promotors that led the youth groups, which are presented in Table 2. These responses reveal that engaging youth is more difficult (relative to engaging mothers) because unlike mothers, youth 'are forced to be here.' Perhaps because of this dynamic in which youth do not elect to join the group, the promotors comment that the youth benefit from different means of engagement in the program, such as 'using video clips,' 'listening to music, playing games and having fun all together.' Promotors also mention that when the dynamics in the group are difficult, meeting with families outside of the group enables them to 'build a more trustful relationship with mothers and children.' Finally, the promotors state that even when it may not seem like their work is well-received or percolating within the youth's consciousness, to effectively 'capture and understand the concepts of the study' importantly, through this group process, youth 'are building their support network.'

Next we examine the responses from promotors who led the mothers group, which are presented in Tables 3 and 4. The promotors described both opportunities and challenges, but on the whole were more optimistic. They described working with the mothers, described the groups as being an 'inspiration,' with each family showing a 'story of resilience and love to confront everyday situations.' The promotors described mothers as being engaged participants - they were 'interested in the program,' 'punctual,' full of 'positive energy,' felt the information they received was 'important' for their families and shared a 'variety of testimonials and experiences.' The promotors also articulated some challenges that they encountered, especially in terms of working with mothers who had experienced such tremendous adversity in their lives. They described the difficulties of working with mothers who have 'gone through very difficult losses' and the challenges this creates in 'transmit(ing) a message' regarding secure base and safe haven to mothers who had not themselves experienced such a thing. Despite this, the promotors commented that they were moved by the mothers' commitment to nonetheless continue striving to be a better mother despite these challenges. Finally, the promotors commented on the high level of group cohesion, noting that the mothers 'understood each other well,' were able to overcome past differences, begin 'friendly relationships' that can continue beyond the groups, and were on the 'lookout for who was missing' among them. In other words, not only were the groups building connections between mothers and their children, but also among the group members.

\section{RQ2: How do promotors think and feel about the process of co-developing and delivering an attachment-based intervention?}

In the previous section, we discussed the opinions of the promotors as they are related to the quality of the curriculum being presented to the community. In an effort to further explore the experiences of the promotors throughout the process of conducting our study, this section addresses promotor/a experiences with co-developing and delivering the attachment-based curriculum. To address this question, a total of 129 unique verbatims were extracted from the interview transcripts and were compiled in a data table provided to the coding team $(n=4)$ to review and identify occurrences where codes could be applied. Upon completing the coding phase of the analytic approach, 128 unique verbatims were included in the final analysis. Coded verbatims included in the final analysis were determined through establishing coding agreement of $75 \%$ or higher between the four coders for each coded verbatim (see Table 
$\mathrm{S} 1$ in Appendix). Throughout the coding process, verbatims were assigned at least one or more codes; given this approach, coded verbatims are repeated in Table 5 to accommodate multiple codes per a given verbatim. Thus, the totals discussed in the analysis below are inflated as a result (total coded verbatims $=323$ ).

Results from the qualitative analysis show that overall, promotors reported positive experiences from being involved in the development and implementation of the curriculum. We discuss the promotors' experiences through the following themes that emerged from conducting the qualitative analysis. Themes are presented in rank order, starting with the most frequent verbatims on top (see Table 5). Examining frequencies of coded verbatims at the theme level revealed that $36.8 \%$ of the total 323 coded verbatims were coded for takeaways (lessons learned), $11.5 \%$ were coded for engaging youth, and $9.6 \%$ were coded for promotora buy-in. Additionally, frequency values showed that
$7.1 \%$ were coded for community connectedness, $6.8 \%$ were coded for real life application, 6.5\% were coded for parent-child relationships, 5.9\% were coded for engaging mothers, and 5.6\% were coded for engaging promotoras. Finally, $4.0 \%$ were coded for participant retention, $2.2 \%$ were coded for trauma-informed, $2.2 \%$ were coded for attendance and $1.9 \%$ were coded for recruitment.

Takeaways. Overall, promotors enjoyed the experience of co-developing and delivering an attachment-based curriculum. The following verbatims demonstrate the overall takeaways promotors identified as a result of being involved in the program, '... overall, the experience was very positive... leading the workshop and working... with the staff uh some uh [university], it was very, it was a very positive experience.' Promotors expressed that they felt the experience of being involved in the development and implementation of the curriculum was rewarding for them personally, '... for me the experience was really enlightening...

Table 3. Qualitative responses from youth promotors.

\begin{tabular}{|c|c|}
\hline & Youth promotors' takeaways \\
\hline \multirow[t]{16}{*}{ Spanish } & English \\
\hline & $\begin{array}{l}\text { The youth were very closed in the beginning but opened up to us and each } \\
\text { other on the later sessions }\end{array}$ \\
\hline & $\begin{array}{l}\text { After 1-1 Family interventions we were able to build a more trustful rela- } \\
\text { tionship with mothers and children }\end{array}$ \\
\hline & $\begin{array}{l}\text { I felt a connection with this group. Some of the participants said they were } \\
\text { going to miss the program. I received goodbye hugs from } 4 \text { of them. }\end{array}$ \\
\hline & $\begin{array}{l}\text { It's a lot harder to engage youth participants when they are forced to be } \\
\text { here but even with that challenge they turned to be a good group. }\end{array}$ \\
\hline & $\begin{array}{l}\text { Using video clips bringing snacks listening to music playing games and } \\
\text { having fun all together brings us closer as a group }\end{array}$ \\
\hline & $\begin{array}{l}\text { Families that can benefit from a program like this have other Immediate } \\
\text { needs that need further interventions }\end{array}$ \\
\hline & $\begin{array}{l}\text { Definitely facilitating an activity during graduation day in which everyone } \\
\text { participates really brings a sense of community. }\end{array}$ \\
\hline & $\begin{array}{l}\text { Youth capture and understand the concepts of the study. Even when we } \\
\text { thought they were not paying attention or participating. In the reviews } \\
\text { they were able to explain the concepts including the circle of security. }\end{array}$ \\
\hline & $\begin{array}{l}\text { Youth were able to share the space, participate and have fun even with the } \\
\text { age differences in the group. }\end{array}$ \\
\hline & $\begin{array}{l}\text { Youth will make connection with other youth even if what they have in } \\
\text { common is a struggle in their homes or in their neighbourhoods. But they } \\
\text { are building their support network. }\end{array}$ \\
\hline & That they actually got along(group) \\
\hline & Always be open for everything \\
\hline & That all kids deserve to be heard. \\
\hline & Teenagers are awesome little adults \\
\hline & $\begin{array}{l}\text { The youth were very closed in the beginning but opened up to us and each } \\
\text { other on the later sessions }\end{array}$ \\
\hline
\end{tabular}

Que todos se llevaron muy bien y los niños son muy tranquilos y participativos

Que todos los niños merecen ser escuchados 
Table 4. Qualitative responses from mother promotors.

\begin{tabular}{ll}
\hline Spanish & Mother promotors' takeaways \\
\hline $\begin{array}{l}\text { Todas las madres de familia siempre tienen retos en su vida pero el amor hacia } \\
\text { sus hijos y a ellas mismas les ayuda a salir adelante }\end{array}$ & $\begin{array}{l}\text { All mothers always have challenges in their life, but the love towards their } \\
\text { children and to themselves helps them move forward }\end{array}$ \\
\hline $\begin{array}{l}\text { Cada familia es una historia de resliencia y amor para enfrentar las situaciones } \\
\text { del dia a dia }\end{array}$ & $\begin{array}{l}\text { Each family is a story of resilience and love to confront everyday } \\
\text { situations }\end{array}$ \\
\hline $\begin{array}{l}\text { La importancia de que las participantes empiezan una relcion de amistad que } \\
\text { pueda continuar despues de estas clases. El apoyo moral es muy importante } \\
\text { parar no sentirte sola }\end{array}$ & $\begin{array}{l}\text { The importance that the participants start a friendly relationship that can } \\
\text { continue after these classes. Moral support is very important for one not } \\
\text { to feel alone }\end{array}$ \\
\hline $\begin{array}{ll}\text { Se hizo un trabajo muy bueno por parte de todo el grupo de UCI y LHA } \\
\text { Aprendi mucho de cada una de ellas fueron una inspiracion para mi }\end{array}$ & $\begin{array}{l}\text { It was a job very well done by all the group from UCI and LHA } \\
\text { I learned a lot from each one of them. They were an inspiration for me. }\end{array}$ \\
\hline $\begin{array}{l}\text { That everyone got along very well, and the kids were very calm and } \\
\text { participated. }\end{array}$ \\
\hline $\begin{array}{l}\text { Definitely facilitating an activity during graduation day in which everyone } \\
\text { participates really brings a sense of community. }\end{array}$
\end{tabular}

Para mi lo interesante fue hablar con los padres y escuchar diferentes idas For me, what was interesting was speaking with the parents and listen to de ellos their different ideas

Me llevo lo de base segura y refugio seguro My takeaway is secure base and safe haven

Que los participantes estan muy interesados con el programa That the participants are very interested in the program

When moms are given a chance to give back, they will give back. In this case they did by sharing great home cooked food.

Que las mamas no tuvieron en sun niñez una base segura ni un refugio seguro

That the moms did not have a secure base nor safe haven in their childhood

El grupo era grande (16 participantes) hubo variedad de testimonio y experiencias. Muy enríquecedor!

The group was big (16 participants). There was a variety of testimonials and experiences. Very enriching!

Ella identificaron cosas en común como los gustos de sus hijo

The punctuality of this group and since the first day, one could see the positive energy among them.

Fue un grupo muy bueno y participativo a pesar de ser muchas

The women understood each other very well

La Sra XXXX expreso lo importante que era para ella recibir esta informacion $\mathrm{y}$ todo lo que le estaba ayudando con su hija todos estos conocimientos

Mrs. XXXX expressed how important it was for her to receive this information and how much this knowledge was helping her with her daughter

Es un grupo muy nice

It is a very nice group

En definitiva es un buen grupo que me dejo pensando en como crear mas herramientas para ayudarlas a conseguir la conexion de ellas con sus hijos

In all, it is a good group that left me thinking how to create more tools to help them obtain their connection with their children

Siempre estuvierón pendiente de quien faltaba a clase...

La tolerancia que tuvieron dos participantes en el grupo, fuera han tenido problemas en el pasado

They were always on the lookout of who was missing class...

Los distintos niveles emocionales que ellas cuentan en sus historias y lo dificil The distinct emotional levels that they tell in their stories and how difficult que es tratar de transmititr un mensaje del cual no se ha tenido experiencia en el pasado, como sucedio con este grupo al no conectarse con una base segura o un refugio seguro

La receptividad fué muy buena

Fue un grupo bastante bueno, trabajaron muy bien los cuestionarios sobre las remembranzas en sus hijos

No estan complicado los grupos. tan grandes, pero el salon de clase debe ser + comodo. Me gusto!

The tolerance that two participants had in the group. Outside, they have had problems in the past

it is to try to transmit a message of which no experience has been had in the past, like it occurred with this group by not connecting with a secure base or safe haven

The receptiveness was very good

Getting to know more people and their life stories that allowed me to learn more every day

Getting to know women who have gone through very difficult losses and their desire to continue being a better mom every day and that they never lose faith, that it is possible to find good people who can support you in your life

He aprendido que cada grupo ha tenido sus propias caracteristicas, y que aunque fue al azar muchas veces parecia que los grupos fueron escojidos los participantes por las caracteristicas casi iguales con referencia a las experiencias en la vida

I learned that each group has had their own characteristics and that even though it was random a lot of the time, it seemed like the groups were chosen by the participants for their almost equal characteristics in regard to their life experiences 
was really rewarding to... see the small like minute changes that you see week to week in each of... the individual youth... that part was definitely... the reward from it.' Finally, promotors reflected on the true impact of the program on the community through sharing a story about a mom who returned to the agency, expressing gratitude for the services provided in this program. The mom continued by explaining that before the program, her child was very rebellious and that after participating in this program her son is a completely different kid, '... I... had a conversation... with a lady... who was in the group and was telling me... 'thank you for inviting me to this class... when I got there my child was very rebellious... and now after this class... I don't know what they told him, I don't know how they worked with him... my son is another child completely... 'the promotora continued to explain that the mother said,'... and now he's doing very well in school... we're doing well at home, he supports me a lot... he supports his siblings... I don't know what they told him or how they worked with him, but, it has worked a lot for me.'

Engaging youth. Promotors also reflected on strategies they found helpful for engaging youth. Promotors identified the benefit of providing creative outlets for youth group participants, '... we would need to... put something... more interesting for them... something more based on art... something fun for them... it would have to be something very... striking for them, like, that... they were really interested in and - and that would get them out of thinking about other things.' While the curriculum did incorporate the use of art and role-playing throughout the program, promotors identified a need to get more creative with the implementation of the curriculum particularly when engaging youth: '.. we had a activity in which... [the youth] ... had to roleplay different roles... and... it would've been really cool... to like to make a TikTok or make a video... that they could share with the group where they're not in front of the group pre-

Table 5. Frequency of themes in rank order.

\begin{tabular}{llcc}
\hline Rank & Theme & \multicolumn{2}{c}{ Total coded verbatims } \\
& & Freq. & Freq. $\%$ \\
\hline 1 & Takeaways & 119 & $36.8 \%$ \\
\hline 2 & Engaging youth & 37 & $11.5 \%$ \\
\hline 3 & Promotora Buy-in & 31 & $9.6 \%$ \\
\hline 4 & Community connectedness & 23 & $7.1 \%$ \\
\hline 5 & Real life application & 22 & $6.8 \%$ \\
\hline 6 & Parent-child relationships & 21 & $6.5 \%$ \\
\hline 7 & Engaging mothers & 19 & $5.9 \%$ \\
\hline 8 & Engaging promotoras & 18 & $5.6 \%$ \\
\hline 9 & Participant retention & 13 & $4.0 \%$ \\
\hline 10 & Trauma informed & 7 & $2.2 \%$ \\
\hline 11 & Attendance & 7 & $2.2 \%$ \\
\hline 12 & Recruitment & 6 & $1.9 \%$ \\
\hline
\end{tabular}

senting... ' In addition to providing youth with a creative outlet, promotors also identified the importance of making time for team building when working with youth to help initiate new relationships, '... the way that the curriculum currently is... it works out perfectly in terms of how the kids are able to establish bonding... we dedicated time to... team building at the beginning... of the sessions. So definitely, I think ... to specifically make time for that.'

Promotor/a buy-in. Next, promotora engagement was also measured through providing opportunities for promotors to 'buy-in' to the curriculum. Promotors felt positively about being able to make contributions to the curriculum and expressed appreciation for being provided with an opportunity that may not have been offered to other promotors in similar situations, '... we really liked having that opportunity... it helped us to... contribute ideas and contribute ways of transmitting the message that we probably don't have the option to in other programs. And that was very good.'

Parent-child relationships. Promotors were given the opportunity to provide feedback regarding their opinions of the final product. In describing their experiences, they highlighted the significance of strengthening parent-child relationships and discussed ways in which they were able to apply what they learned to their own families. Promotors identified the opportunity for mothers to learn something different in their relationship with their child as a strength of the curriculum: 'They gave moms the opportunity to learn something different regarding the relationships with their adolescent child.' Promotors also expressed that they believe families made changes to the way they care for their child as a result of the focus on parent-child relationships in the curriculum: 'I think that... they understood many things once the child's developed, and how they saw it and how it really is. I think that they made various changes in the way... of nurturing the relationship with the child and to improve it.' Promotors thought that '(mothers) understood a lot about the child's development, and how they saw it and what it really is like... I think they made... various changes in the way... of nurturing the relationship with the child and to improve it.' Additionally, promotors identified the attachment-based content of the curriculum as a strength in addressing challenges that exist between mother and youth, '... the strengths were... [secure] base... and safe haven ... they began to understand... that whenever their children would go through certain difficulties they would return to them. And they... could help them... Then from those moments they have already begun to - to observe and listen better to their children.' Promotors recognized the need for the Latinx community to learn more about strengthening their relationships with their children -'... we as a Latinx community need... to know our children more... know what their interests are... what goals they have. This... is something basic... for us as parents... to know more about... our children... Because at times, we think that we know our children and we know nothing...' 
Engaging mothers. In regard to families participating in the program, promotors identified the important social aspect of bringing a group of mothers together for the class. They thought the class provided valuable information for mothers and expressed that mothers enjoyed being able to share and listen to each other's stories. Taking time to build relationships between the mothers was an important aspect of mother engagement: 'I think... [it]was valuable information for moms. They enjoyed class time, were able to share and hear stories, and were also able to generate... relationships between them... that was very important as well.' The content of the curriculum also engaged mothers participating in the program. Promotors identified that mothers always had a good disposition and that they enjoyed learning about the details of the parent-child relationships that they had not considered before, '... the moms were always willing, the moms always... had good disposition and they really enjoyed... learning about... certain details that they have never observed... nor have imagined... those details were important for their relationships...

Engaging Promotors. Promotor/a engagement was evaluated based on promotors reflecting on their experience co-developing the curriculum protocol. Promotors expressed feeling engaged through being given the space to make contributions to the curriculum through reviewing the manual and providing recommendations for improvements. Promotors recalled making contributions to the curriculum, 'I feel like I was able to contribute... we got the chance to review it, gave our input and... most of the things that we requested... did end up in the curriculum.' Additionally, promotors felt that they were listened to and were included in the conversation related to any suggested revisions to the curriculum, '... I think my opinions... were definitely listened to and... anytime that any revisions...[were] made... we had to facilitate some kind or conversation... I definitely think I was included in the process.'

Community connectedness. Promotors identified the important role of community connectedness in attributing program impact. Promotors identified the need for belonging for the Latinx immigrant community specifically: '... you come to... a different country where you don't speak the language, and everyone is... focused on trying to survive... you don't even know your neighbours... there's a huge need... of... belonging to - to something...' The promotors explained that this need for connectedness was evident at the family dinner held at the end of each program '... I could see that when we got together in... those dinners that we had with the families... they are happy to contribute... I think because of that same feeling of... wanting to belong to... the community or a group...'

Real life application. Promotors identified the relevance of the curriculum as a strength, highlighting the tools they were able to develop as a result of what they learned from the curriculum, 'now that I'm a father... all these things that I've learned throughout my work at Latino Health Access... and of course... this program among those... I feel that I have a lot of tools.' Additionally, promotors acknowledged the importance of learning about topics like attachment to be able to put what they learned into practice with their families, '... I felt motivated too... to continue with... these concepts that you brought, like secure base, safe haven... I practice it a lot with my children... They know that they can always count on me... for whatever they need... and that's exactly what I admit to the families too when I talk to them.'

Participant retention. Promotors feared that the time intensive interview process would deter families from continuing with the program, suggesting that families may would think every session would be the same as the interviews, 'And that was worrisome, that... so few came to the first class, probably thinking, that all the... classes would be in the same style.' While promotors expressed appreciation for the process of conducting interviews with the families to support program evaluation efforts, they were concerned that the interviews were too long and tedious for the families and also stressed that families were confused and did not always understand the question clearly, '... The evaluations were too long... - in the long run they had to remove questions and all this because it was very repetitive. And the way in which the questions were also designed, people questioned a lot, they did not understand the question clearly.' In addition to identifying the evaluation process as a barrier, promotors also expressed concern for the cost to conduct outreach, '... it cost so much... the outreach was very hard... we would bring, I don't know, 30 people... and when we would do the classes... 18 would come and... by the second class... there was a drop off... And sometimes... only 8 would come or $6 .$. ' Promotors also expressed the length of the program as a barrier to participant retention when implementing the program. 'I think having too many sessions... could be a weakness... like retention is very, very hard... it's not easy...I would've made it shorter, maybe four sessions or five, at the most.'

Trauma-informed. Promotors identified the importance of building trauma-informed competencies when working with Latinx youth and mothers. For mothers, promotors observed that reflecting on attachment-based themes like 'safe haven' and 'secure base' was often a hard concept for mothers to understand as a result of their own trauma histories, 'we... had a complete group of moms... that were not connecting... safe haven and...[secure] base... Because they were mothers who in their childhood... had too much violence... . and too much abuse of the adults around them with whom they grew up. So they didn't connect that part...' For youth, promotors reflected on potential for 'emotional flooding' as a result of the curriculum, demonstrating a need for more opportunities to have one-on-one sessions with youth in community settings, '... we have to... note that they are... youth with a possible history of trauma or witnessing trauma... So, um a lot of like emotional flooding sometimes I would see that they wouldn't want to engage because it was just too much to think about.' 
Attendance. Promotors identified the timing of the availability of the classes as a barrier to participant attendance, '... with... kids showing up later... it had to do with time... we would start 5-5:30 and then we would end up doing 'till 6 so everybody got around to - make it to the agency and be in their little classroom.' Participant work schedules contributed to participant attendance for both mothers and youth, '... sometimes the people for work reasons arrived... a little late or they couldn't attend for certain reasons... they wouldn't arrive on time, they left their job late... and they came running to the class. They were already making a great effort to be present.' Promotors identified participant attendance as an impact to overall group dynamics as well, '... sometimes... maybe not every week not every youth shows up... they're absent a few weeks, or a couple of weeks, or a week... and you can tell... how it changes a little bit of... their connectedness with other youth in the group...'

Recruitment. Promotors identified the evaluation process as a challenge to recruiting families to participate in the program, '... . at the beginning [it] was really hard for us to get... participation from our community... because... a lot of 'em... felt intimidated being recorded and... some of the questions were... too invasive... maybe it was more of a learning experience.'

Promotors reflected on the impact of delivering an attachment-based curriculum within their community. Promotors highlighted the benefits of feeling connected to the community as a result of delivering the program. Furthermore, promotors expressed positive experiences reported by the community as a result of participating in the program.

\section{Discussion}

The purpose of this study was to examine the experiences of promotors involved in co-designing and delivering an attachment-based intervention to youth and their mothers. Attachment-based interventions are grounded in theory and research, but to date they have not been integrated with the cultural values of historically marginalized communities, nor have they been designed in collaboration with members of these communities. Failing to incorporate the input of community members risks creating intervention programs that are inconsistent with the cultural values of Latinx communities, whereas involving community members from the inception creates opportunities to design programs that are inclusive and represent the needs and values of the community. The current program is innovative in its inclusion of promotors at the centre of the design process - as purveyors of local knowledge, their input was privileged, valued, and weighed heavily. Understanding their experience in undergoing this design and intervention delivery process will be invaluable in assisting researchers who seek to accomplish similar goals of incorporating community voices into the design and delivery of their attachment programs.

\section{Intervention group quality}

We pursued two central aims in this study. First, we assessed promotors' evaluations of the quality of the intervention program. Our findings revealed that on the whole, the promotors perceived the intervention to be moderately high in quality. We qualify this statement by also noting that in general, the promotors reported that the mother groups were higher in quality than the youth groups (higher levels of connection between group members, better quality relationships between group members, greater program relevance, and lower levels of conflict). The qualitative data shed additional light on the impressions gleaned from the quantitative data - the youth were more difficult to engage in the curriculum, perhaps because they were not the ones who had made the choice to attend the program (their mothers had made the choice to attend). Further, youth are less likely to engage in discussion-based tasks and enjoy the tasks that involve multimedia (e.g., videos, songs, activities).

Our curriculum was focused primarily on being culturally congruent with the experiences and perspectives of recent immigrant Latinx mothers. Several explanations come to mind in terms of what may be reflected in these differential trends between youth and mother groups. First, because our efforts were devoted to the engagement and retention of immigrant Latinx mothers, we may have failed to acknowledge the likely strong influence of the varying levels of acculturation and acculturative experiences between youth and their mothers. Secondly, a prominent and very likely explanation for this trend may stem from developmental differences between the youth in our sample. Moreover, our youth groups hosted children and adolescents between the ages of 8 and 17; it is well known in the field that, in general, older youth are more difficult to engage and retain within research and intervention settings relative to their younger counterparts (Villarruel et al., 2006). Lastly, while our sample as a whole must contend with many adversities, older youth tend to experience greater risk exposure (Liu et al., 2018), meaning that differing levels of risk exposure may also be influencing the dynamics within our youth groups. In sum, a combination of factors may have rendered the intervention less culturally congruent for youth, underscoring the need for modifications to enhance engagement in the future.

Notably, in our co-design process, we did not include any youth. The youth promotors (who were included in the co-design process) are all adults, and this design flaw may have trickle down effects on the quality of the programming for youth. Including youth in a future co-design revamping process of the youth programming would be a way to improve the overall program. If we were to revamp the program, we might wish to incorporate more multimedia-based activities into the youth program. One idea we had floated early on, suggested by one of the youth promotors, was having the youth video record moments 
from their lives that signified the experiences we were discussing in the group (e.g., moments of positive connection, moments of experienced secure base and safe haven support). The youth could then take these recorded moments and weave them into a TikTok-like video clip that they present to the group at the end of the program. We ended up not pursuing this idea due to resource constraints, but this would be something worth reconsidering going forward.

In terms of the mother groups, the feedback from the promotors was largely positive. A central theme that emerged from the feedback was that the connections formed between the group members were powerful and important forces in driving change. Such findings align with distinctive features of convivial collectivism, which emphasizes active engagement and response in both supportseeking and support-giving behaviours as a means of building and affirming relational bonds in Latinx communities (Campos \& Kim, 2017). These relationships formed between group members is one reason to choose group therapy as a format over individual therapy (Ford et al., 2009) - sharing experiences can be a powerful experience that reduces stigma, creates a sense of shared identity and hope, increases social support, and drives change. Interestingly, within both the mother and the youth groups, stronger relationships between group members were positively linked with promotors' positive feelings of connectedness with the group members. In other words, when promotors felt positively connected to the groups they were leading, they also perceived the group members to have built strong relationships with one another. This pattern of association leads us to believe that given the interrelatedness of promotor/a-group member and group members-group member relationships, finding ways to support promotors' connectedness to group members may be important in future iterations of this and other attachment-based co-designed interventions.

\section{Reflections on the co-design and intervention delivery process}

Our second aim was to evaluate promotors' impressions of the entire co-design and intervention delivery process from start to finish, as well as the resultant intervention, based on interviews conducted with them at the end of the 4 year collaboration process. This aim involved utilizing thematic analysis of these interviews, which revealed the following themes: i) Takeaways (community impact); ii) Engaging youth; iii) Promotor/a buy-in; iv) Community connectedness; v) Real life application; vi) Parent child relationships; vii) Engaging mothers; viii) Engaging promotors; ix) Retention; $\mathrm{x}$ ) Trauma; xi) Attendance; and xii) Recruitment. It is important to note the significance of the themes as they are presented in rank order starting with the themes that appeared most frequently (e.g., Takeaways, Engaging Youth, and Promotor/a buy-in). Promotor/a reflections on lessons learned (takeaways) highlighted the importance of community impact when collaborating in the process of program development and implementation. Most notably, promotors described the community impact through sharing positive testimonials provided by parents in the community. Acknowledging the relational nature of the themes that emerged throughout the coding process (e.g., youth, mother, and promotor/a engagement), and identifying which coded verbatims appeared most frequently provides insight into the priorities of the promotors in supporting the Latinx community, demonstrating the unique contribution of cultural values like familismo in delivering an effective intervention program.

In terms of Program Development, an encouraging finding from this analysis was that the promotors endorsed feeling included in the co-design process, acknowledging that the resultant curriculum reflected their input, beliefs, and wisdom. This suggests that the process of meeting and reviewing the curriculum with the academic team, revising it based on promotor/a input, and then reviewing again, was ultimately successful in achieving the goals of representing the views and insights of the local knowledge represented by the promotors. In terms of Program Implementation, promotors discussed the process of engaging mothers and youth in the program, identifying different means of engaging of these two groups - for mothers, the connections with other groups members and the relationships they built with them was engaging, whereas for youth, the activities (e.g., art, digital media, opportunity for expression) were engaging, though this was an aspect of the program that could be further reinforced. Promotors recognized the need to acknowledge the impact of clients' trauma experiences on their ability to absorb the information discussed in the groups, as well as the need for additional supportive services (e.g., one-on-one sessions with participants, individual sessions between promotors and mother-youth dyads). In future programming with traumatized populations, additional resources should be allocated for adjunctive services (e.g., triaging of cases, supplemental family and individual therapy sessions with promotors and/or mental health clinicians) - providing these additional supports could facilitate greater progress within attachment-based intervention groups and ultimately help the promotors feel more supported. These comments may speak to an underlying need of the promotors to receive more training in approaches to working with traumatized families, particularly when discussing sensitive topics such as safety, security, protection and autonomy support within attachment relationships. Such topics will inevitably lead trauma-exposed individuals to tap into emotions, cognitions, and memories associated with abuse and/or trauma, and it could be helpful to provide training to promotors regarding how to respond effectively to these situations when they arise. Further, these findings raise the idea of the importance of assessing promotors' preparedness to address these issues in a therapeutic context.

The promotors offered valuable suggestions for changing the logistics of the program to increase reten- 
tion, reduce the need for make-up sessions, and increase engagement with the program overall. Taking these suggestions into account along with the promotors' other suggestions, we might want to consider reducing the number of overall sessions from 8 to 4 or 5 and adding on individual or family sessions. We do have session by session data from the program participants regarding their impressions of the program content (note that these data are not presented here) - we can use these data, as well as the feedback from the promotors to help us decide which content is most helpful. In terms of the curriculum itself, the promotors' impressions were consistent in pointing towards the emphasis on strong family relationships (i.e., familismo) as a key ingredient of importance within the intervention. The promotors praised the program for helping mothers and youth think about their relationships in new ways, particularly during the challenging developmental phase of adolescence, and for providing them with tools to interact with one another in different ways. These perspectives are consistent with the intended goals of an attachment-based program (Pace et al., 2016; Steele et al., 2014) - increasing insight regarding the importance of strong and secure parent-child relationships and to change behaviour in these relationships so that it results in greater responsiveness to children's distress and support for children's autonomy.

On a broader level, the program had an impact on and can be contextualized as being important within the community. Given the current cultural moment in which Latinx immigrant families have experienced horrific discrimination and threats of deportation (Cardoso et al., 2021) and been treated as unwelcome within the United States (Ayón, 2020), members of this community have a need to belong, as articulated so clearly by one of the promotors interviewed for this study. This program enabled the families a feeling of belonging, creating a microcosm of the very principles it was developed to engender in the families.

\section{Strengths and limitations of the current study}

The strengths of this study include the examination of an understudied population (promotors) who are integral to health care promotion within low income immigrant communities, as well as the use of multiple methods (quantitative and qualitative) to address research questions, assessed at various points throughout the study (after each intervention group, at the end of the entire investigation), and the use of assessments delivered in language of participants' choice. The weaknesses of this study include the inclusion of a small number of participants and the fact that we examined promotors working with one intervention program at one community agency. These aspects of the study may limit the external validity of the investigation, calling for future studies examining the experiences of promotors engaged in this type of co-design and intervention delivery work at other community agencies. Further, the fact that the promotors were interviewed by members of the research team may have precluded them from being as forthright as they might have been had they been interviewed by impartial parties. At the same time, qualitative methods underscore the importance of developing relationships between interviewer and participant prior to conducting interviews in order to enhance participant comfort.

\section{Conclusions}

The results of this study provide important insight into promotors' experiences co-developing and delivering an attachment-based intervention to youth and mothers within a community agency serving low income Latinx immigrant families. The conclusions are clear: i) this co-developed intervention has high cultural congruence and high levels of appeal for mothers in particular; ii) it positively impacted the work and personal lives of the promotors and the participants; iii) finally, adjusting the youth curriculum to increase its cultural congruence would likely enhance engagement.

\section{References}

Ainsworth, M. D. S., Blehar, M. C., Waters, E., \& Wall, S. (1978). Patterns of attachment: A Psychological study of the strange situation. Lawrence Erlbaum.

Alhusen, J. L., Hayat, M. J., \& Gross, D. (2013). A longitudinal study of maternal attachment and infant developmental outcomes. Archives of Women's Mental Health, 16, 521-529. doi:10.1007/s00737-013-0357-8.

Arredondo, E. M., Dumbauld, J., Milla, M., Madanat, H., Coronado, G. D., Haughton, J., Garcia-Bigley, F., Ramers, C., Nodora, J., Bharti, B., Lopez, G., Diaz, M., Marquez, J., \& Gupta, S. (2021). A promotor-led pilot study to increase colorectal cancer screening in Latinos: The Juntos Contra el Cáncer program. Health Promotion Practice, 22(4), 491-501.

Ayón, C. (2020). State-level immigration policy context and health: How are Latinx immigrant parents faring? Social Work Research, 44(2), 110-122.

Bakermans-Kranenburg, M. J., van IJzendoorn, M. H., \& Juffer, F. (2003). Less is more: Meta-analyses of sensitivity and attachment interventions in early childhood. Psychological Bulletin, 129(2), 195-215.

Barnett, M. L., Gonzalez, A., Miranda, J., Chavira, D. A., \& Lau, A. S. (2018). Mobilizing community health workers to address mental health disparities for underserved populations: A systematic review. Administration and Policy in Mental Health, 45(2), 195-211. doi:10.1007/s10488-017-0815-0.

Barnett, M., Miranda, J., Kia-Keating, M., Saldana, L., Landsverk, J., \& Lau, A. S. (2019). Developing and evaluating a lay health worker delivered implementation intervention to decrease engagement disparities in behavioural parent training: a mixed methods study protocol. BMJ Open, 9(7), e028988. doi:10.1136/bmjopen-2019-028988.

Beijersbergen, M. D., Juffer, F., Bakermans-Kranenburg, M., \& van IJzendoorn, M. H. (2012). Remaining or becoming secure: Parental sensitive support predicts attachment continuity from infancy to adolescence in a longitudinal adoption study. 
Developmental Psychology, 48(5), 1277-1282. doi:10.1037/ $\mathrm{a} 0027442$.

Borelli, J. L., Cervantes, B. R, Hecht, H. K., Marquez, C., DePrado, R., Torres, G., Robles, A., Chirinos, N., Leal, F., Montiel, G. I., Pedroza, M., \& Guerra, N. (2021). Barreras y soluciones: Lessons learned from integrating research-based clinical techniques into a community agency serving low-income Latinx immigrant families. Family Process. [In press].

Borelli, J. L., Yates, T. M., Hecht, H. K., Cervantes, B. R., Russo, L. N., Arreola, J., Leal, F., Torres, G., \& Guerra, N. (2021). Confía en mí, confío en ti: Applying developmental theory to mitigate sociocultural risk in Latinx families. Development and Psychopathology, 33(2), 581-597. doi:10.1017/ S0954579420001364.

Bowlby, J. (1973). Attachment and loss, Vol. 2: Separation. New York: Basic Books.

Bracho, A., Lee, G., Giraldo, G. P., \& De Prado, R. M. (2016). Recruiting from the heart, training the brain: The work of Latino Health Access. Hesperian Foundation.

Braun, V., \& Clarke, V. (2012). Thematic analysis. In H. Cooper, P. M. Camic, D. L. Long, A. T. Panter, Bruckner, T. A., Scheffler, R. M., Shen, G., Yoon, J., Chisholm, D., Morris, J., Fulton, B. D., Dal Poz, M. R., \& Saxena, S. (2011). The mental health workforce gap in low- and middle-income countries: a needs-based approach. Bulletin of the World Health Organization, 89(3), 184-194. doi:10.2471/BLT.10.082784.

Campos, B., \& Kim, H. S. (2017). Incorporating the cultural diversity of family and close relationships into the study of health. American Psychologist, 72, 543-554. doi:10.1037/ amp0000122.

Campos, B., Ullman, J. B., Aguilera, A., \& Dunkel Schetter, C. (2014). Familism and psychological health: The intervening role of closeness and social support. Cultural Diversity and Ethnic Minority Psychology, 20(2), 191-201. doi:10.1037/a0034094.

Cardoso, J. B., Brabeck, K., Capps, R., Chen, T., Giraldo-Santiago, N., Huertas, A., \& Mayorga, N. A. (2021). Immigration enforcement fear and anxiety in Latinx high school students: The indirect effect of perceived discrimination. Journal of Adolescent Health, 68(5), 961-968. doi:10.1016/j.jadohealth. 2020.08.019.

Campbell, J. L., Quincy, C., Osserman, J., \& Pedersen, O. (2013). Coding in-depth semistructured interviews: Problems of unitization and intercoder reliability and agreement. Sociological Methods and Research, 42, 294-320. doi:10.1177/ 0049124113500475.

Cicchetti, D., Rogosch, F. A., \& Toth, S. L. (2006). Fostering secure attachment in infants in maltreating families through preventive interventions. Development \& Psychopathology, 18(3), 623-649. doi:10.1017/s0954579406060329.

Dagnino, P., Perez, C., Gomez, A., Gloger, S., \& Krause, M. (2017). Depression and attachment: How do personality styles and social support influence this relation? Research in Psychotherapy: Psychopathology, Process and Outcome, 20, 5362. https://doi.org/10.4081/ripppo.2017.237

Del Villano, N., Cecere, C., Sapuppo, W., Sannino, A., Perrella, R., Bisogno, S., \& Caviglia, G. (2014). Working memory abilities, attachment relationships an learning process in children of primary school age: An empirical research. Research in Psychotherapy: Psychopathology, Process and Outcome, 17(1), 21-32. doi:10.4081/ripppo.2014.134.

D’Onofrio, E., Pace, C. S., \& Cavanna, D. (2015). Qualitative research in adolescent psychotherapy: attachment and reflective functioning as psychotherapy outcomes of an adolescent with anorexia nervosa. Research in Psychotherapy: Psychopathology, Process and Outcome, 18(2), 93-101. doi:10.4081/ ripppo.2015.181.

Diamond, G. S., Wintersteen, M. B., Brown, G. K., Diamond, G. M., Gallop, R., Shelef, K., \& Levy, S. (2010). Attachmentbased family therapy for adolescents with suicidal ideation: A randomized controlled trial. Journal of the American Academy of Child \& Adolescent Psychiatry, 49(2), 122-131. doi:10.1016/j.jaac.2009.11.002.

Dozier, M., \& Kristin, B. (2017). Attachment and biobehavioral catch-up: Addressing the needs of infants and toddlers exposed to inadequate or problematic caregiving. Current Opinion in Psychology, 15(3), 111-117. doi:10.1016/j.copsyc. 2017.03.003.

Elder, J. P., Ayala, G. X., Parra-Medina, D., \& Talavera, G. A. (2009). Health communication in the Latino community: issues and approaches. Annual Review of Public Health, 30, 227-251. doi:10.1146/annurev.publhealth.031308.100300.

Falbe, J., Friedman, L. E., Sokal-Gutierrez, K., Thompson, H. R., Tantoco, N. K., \& Madsen, K. A. (2017). 'She gave me the confidence to open up': Bridging communication by promotoras in a childhood obesity intervention for Latino families. Health Education \& Behavior, 44(5), 728-737. doi:10.1177/ 1090198117727323.

Ford, J. D., Fallot, R. D., \& Harris, M. (2009). Group therapy. In C. A. Courtois \& J. D. Ford (Eds.), Treating complex traumatic stress disorders: An evidence-based guide (pp. 415440). The Guilford Press.

Hahn, H., Oransky, M., Epstein, C., Smith Stover, C., \& Marans, S. (2015). Findings of an early intervention to address children's traumatic stress implemented in the child advocacy center setting following sexual abuse. Journal of Child \& Adolescent Trauma, 9(1), 55-66. doi:10.1007/s40653-0150059-7.

Held, M. L., Nulu, S., Faulkner, M., \& Gerlach, B. (2020). Climate of fear: Provider perceptions of Latinx immigrant service utilization. Journal of Racial and Ethnic Health DisParities, 1-12. doi:10.1007/s40615-020-00714-w.

Hoeft, K. S., Rios, S. M., Guzman, E. P., \& Barker, J. C. (2015). Using community participation to assess acceptability of 'Contra Caries', a theory-based, promotora-led oral health education program for rural Latino parents: a mixed methods study. BMC Oral Health, 15(1), 1-11.

Infante, A., Knudson, A., \& Brown, A. (2011). Promising practices for rural community health worker programs. Walsh Center for Rural Health Analysis. Available from: https://www.norc.org/PDFs/Walsh\%20Center/Rural\%20Eval uation\%20Briefs/Rural\%20Evaluation\%20Brief_March2011 Yseries 1.pdf

Israel, B. A., Schulz, A. J., Parker, E. A., \& Becker, A. B. (1998). Review of community-based research: assessing partnership approaches to improve public health. Annual Review of Public Health, 19, 173-202. doi:10.1146/annurev.publhealth. 19.1.173.

Kakuma, R., Minas, H., van Ginneken, N., Dal Poz, M. R., Desiraju, K., Morris, J. E., Saxena, S., \& Scheffler, R. M. (2011). Human resources for mental health care: current situation and strategies for action. Lancet, 378(9803), 1654-1663. doi:10.1016/S0140-6736(11)61093-3.

Kataoka, S., Novins, D. K., \& DeCarlo Santiago, C. (2010). The practice of evidence-based treatments in ethnic minority youth. Child and Adolescent Psychiatric Clinics of North 
America, 19(4), 775-789. doi:10.1016/j.chc.2010.07.008.

Kerns, K. A., \& Brumariu, L. E. (2014). Is insecure parent-child attachment a risk factor for the development of anxiety in childhood or adolescence? Child Development Perspectives, 8(1), 12-17. doi:10.1111/cdep.12054.

Kerns, K. A., Mathews, B. L., Koehn, A. J., Williams, C. T., \& Siener-Cieslam S. (2015). Assessing both safe haven and secure base support in parent-child relationships. Attachment and Human Development, 17(4), 337-353. doi:10.1080/14616734.2015.1042487.

Kia-Keating, M., Santacrose, D. E., Liu, S. R., \& Adams, J. (2017). Using community-based participatory research and human-centered design to address violence-related health disparities among Latino/a youth. Family \& Community Health, 40(2), 160-169. doi:10.1097/FCH.0000000000000145.

LeBreeton, J. M. \& Senter, J. L. (2007). Answers to 20 questions about interrater reliability and interrater agreement. Organizational Research Methods, 11(4), 815-852. doi:10.1177/ 1094428106296642.

Lee, J., Hong, J., Zhou, Y., \& Robles, G. (2020). The Relationships between loneliness, social support, and resilience among Latinx immigrants in the United States. Clinical Social Work Journal, 48(1), 99-109. doi:10.1007/s10615-019-00728-w.

Liu, S. R., Kia-Keating, M., \& Nylund-Gibson, K. (2018). Patterns of adversity and pathways to health among White, Black, and Latinx youth. Child Abuse \& Neglect, 86, 89-99. doi:10.1016/j.chiabu.2018.09.007.

Martin, M. Y. (2005). Community health advisors effectively promote cancer screening. Ethnicity \& Disease, 15, S14-S16.

Messias, D. K., Parra-Medina, D., Sharpe, P. A., Treviño, L., Koskan, A. M., \& Morales-Campos, D. (2013). Promotoras de Salud: roles, responsibilities, and contributions in a multisite community-based randomized controlled trial. Hispanic Health Care International: The Official Journal of the $\mathrm{Na}$ tional Association of Hispanic Nurses, 11(2), 62-71. doi:10.1891/1540-4153.11.2.62.

Moretti, M. M., Obsuth, I., Craig, S. G., \& Bartoo, T. (2015). An attachment-based intervention for parents of adolescents at risk: Mechanisms of change. Attachment \& Human Development, 17(2), 119-135. doi:10.1080/14616734.2015.1006383.

Pace, C. S., D’Onofrio, E., Guerriero, V., \& Zavattini, G. C. (2016). A proposal for a brief-term post-adoption intervention in the attachment-perspective: A single case study with a lateadopted child and his adoptive mother. Research in Psychotherapy: Psychopathology, Process and Outcome, 19(1), 31-40. doi:10.4081/ripppo.2016.197.

Rastogi, M., Massey-Hastings, N., \& Wieling, E. (2012). Barriers to seeking mental health services in the latino/a community: A qualitative analysis. Journal of Systemic Therapies, 31(4), 1-17. doi:10.1521/jsyt.2012.31.4.1.

Rhodes, S. D., Foley, K. L., Zometa, C. S., \& Bloom, F. R. (2007). Lay health advisor interventions among Hispanics/Latinos: a qualitative systematic review. American journal of Preventive Medicine, 33(5), 418-427. doi:10.1016/j.amepre.2007.07.023.

Rindskopf, D., \& Sher, K. J. (Eds.), APA handbook of research methods in Psychology, Vol. 2. Research designs: Quantitative, qualitative, neuropsychological, and biological (pp. 57-
71). American Psychological Association, doi:10.1037/ 13620-004.

Roelofs, J., Meestersm, C., ter Huurne, M., Bamelis, L., \& Muris, P. (2006). On the links between attachment style, parental rearing behaviours, and internalizing and externalizing problems in non-clinical children. Journal of Child and Family Studies, 15(3), 331-344. doi:10.1007/s10826-006-9025-1.

Ryan, R., O'Farrelly, C., \& Ramchandani, P. (2017). Parenting and child mental health. London Journal Of Primary Care, 9(6), 86-94. doi:10.1080/17571472.2017.1361630.

Shepherd-Banigan, M., Hohl, S. D., Vaughan, C., Ibarra, G., Carosso, E., \& Thompson, B. (2014). 'The promotora explained everything': Participant experiences during a household-level diabetes education program. The Science of Diabetes Self-Management and Care, 40(4), 507-515. doi:10.1177/0145721714531338.

Singla, D. R., Kohrt, B. A., Murray, L. K., Anand, A., Chorpita, B. F., \& Patel, V. (2017). Psychological treatments for the world: Lessons from low- and middle-income Countries. Annual Review of Clinical Psychology, 13, 149-181. doi:10.1146/annurev-clinpsy-032816-045217.

Steele, M., Steele, H., Bate, J., Knafo, H., Kinsey, M., Bonuck, K., Meisner, P., \& Murphy, A. (2014). Looking from the outside in: the use of video in attachment-based interventions. Attachment \& Human Development, 16(4), 402-415. doi:10.1080/14616734.2014.912491.

Sternberg, R. M., Nápoles, A. M., Gregorich, S., \& Stewart, A. L. (2019). Mentes positivas en acción: Feasibility study of a promotor-delivered cognitive behavioral stress management program for low-income Spanish-speaking Latinas. Health Equity, 3(1), 155-161. doi:10.1089/heq.2019.0012.

Tran, A. N., Ornelas, I. J., Perez, G., Green, M. A., Lyn, M., \& Corbie-Smith, G. (2014). Evaluation of Amigas Latinas Motivando el Alma (ALMA): a pilot promotora intervention focused on stress and coping among immigrant Latinas. Journal of Immigrant and Minority Health, 16(2), 280-289. doi:10.1007/s10903-012-9735-y.

Thomas, R., Abell, B., Webb, H. J., Avdagic, E., \& Zimmer-Gembeck, M. J. (2017). Parent-child interaction therapy: A metaanalysis. Pediatrics, 140(3), e20170352. doi:10.1542/peds. 2017-0352.

Thomas, R., \& Zimmer-Gembeck, M. J. (2007). Behavioral outcomes of parent-child interaction therapy and triple p-positive parenting program: A review and meta-analysis. Journal of Abnormal Child Psychology, 35(3), 475-495. doi:10.1007/ s10802-007-9104-9.

Villarruel, A. M., Jemmott, L. S., Jemmott, J. B., \& Eakin, B. L. (2006). Recruitment and retention of Latino adolescents to a research study: lessons learned from a randomized clinical trial. Journal for Specialists in Pediatric Nursing, 11(4). 244250. doi:10.1111/j.1744-6155.2006.00076.x.

Waitzkin, H., Getrich, C., Heying, S., Rodríguez, L., Parmar, A., Willging, C., Yager, J., \& Santos, R. (2011). Promotoras as mental health practitioners in primary care: a multi-method study of an intervention to address contextual sources of depression. Journal of Community Health, 36(2), 316-331. doi:10.1007/s10900-010-9313-y. 